\title{
Rebuild strategy for Coastal Villages with Reasonable Expense
}

\author{
Renjiatai Trial \\ Min-min GUO ${ }^{1, *}$ \\ ${ }^{1}$ Zaozhuang University \\ Beian Road Zaozhuang Shandong, China 277160 \\ *First \& Correspondence author \\ email: 972660131@qq.com \\ Li-ting $\mathrm{ZHOU}^{2}$ \\ Shandong Youth University of Political Science \\ Jinan Shandong, China 250103 \\ Email zlt66188@sohu.com
}

\begin{abstract}
Aims at putting product design into practice, Renjiatai trial is designed to investigate the rebuild model of coastal villages in eastern area of Shandong. Based on the requirements from being both product and art output, we tried to investigate the commercial and art value of the traditional architecture in the updating technological era.
\end{abstract}

Keywords-Green architecture; Rural environment; Organinc recycle; Green tourism

\section{INTRODUCTION}

\section{A. Location and Environment}

Renjiataiis located at Shanhaitian tours and resorts zone in Rizhao city, Shandong province. Surrounded by sea in three sides Renjiatai features delightful weather. With the convenient communication, it is connected to Qingdao, a modern and developed costal city in Shandong province. Visitors will enjoy Ocean Rock Park, Black pine forest, Beach and Harbor, etc.

\section{B. Economics and development}

Renjiatai was a fishing village. Costal ethnic tourism has been introduced and established extraordinarily since 21 century. Beaches as well as ethnic tour and resorts zone have been developed gradually. In addition to the tour of 'Accommodating at village and entertaining in the sea', cultural square and plaza have been established accordingly. Renjiataiis now one of top rated tour and resort zones, serving seafood and accommodation with high quality. With the1000 occupations out of 1380 village wide population, it provides 5440 guest rooms and 16000 beds to accommodate the visitors from all of world.

\section{Products and market}

However, the current tourism products from Renjiatai are still undergoing initial development, which have been encountered tremendous threats from hard-ware facilities, outline and ethnic activity design as well as simplex, lagging marketing.

Nevertheless, stimulations form the worming tourism environment, unique geographic advantages and resources as well as supports from government ensure the prior conditions for the expanding market in Renjiatai area.

\section{GOAL AND CONCEPTION}

Since the main stream of the customers coming form the surrounding cities out of Renjiatai, the trip usually takes1-2 days to accomplish. The entertainment activities mainly focus on the ocean site view and seafood consuming. As a result, the traditional business carried out in Renjiatai area was as simple as just a overnight accommodation. In return, it was not impossible thatthe garden landscape was not necessarily to be considered. Based on this investigation, we aimed at modifying the tourism system for the visitors to stay up to a week. Improvements got involved in both outdoor and indoor environment. By doing these improvements, visitors would be able to experience the real rural life style, by which, to the most extend, relax themselves. Therefore, the service provided by Renjiatai will be optimized dramatically with the improvement of the living environment.

We recommended the tourism design in Renjiatai area to undergo the specialized development to pursue a long-term business. Aesthetic value and green (environmental friendly) design will be infused into the home stay business in Renjiatai trial. Visitors are expected to experience the history, industry, nature, local conditions and customs, as well as natural landscape in Renjiatai area.

In our project, home numbers 5,6,7,11,12,13,14 have been chosen randomly for the experimental remodel. Our design follows the idea of Respect the Nature, Organic and Recycle, Humanism, Overall Coordinate and Integrated Practice. Aiming at developing the outstanding rural homestay business, we explored the existing issues and developing shortages, in return, we proposed a point-to point modification to improve the family business service and, eventually, to shape into a sustainable developmental costal tourism and resorts zone.

\section{STATUS ANALYSIS}

A classic home stay business in Renjiatai costal village is composed of a $15^{*} 15 \mathrm{~m}$ yard with 5 rooms, some of has only 3 rooms or even less. Brick and tile based architectural characteristics are common in this area, in addition, highdensity aliment and routine spatial arrangement were the characters of the buildings in this area. Limited indoor space and single-functional rooms make it impossible for any high quality living products. 
We realized that in order to increase more rooms to accommodate increasing customers, some owners added 1-2 stories in the yard. Thereafter, the yards are meaningless without any plants and openings to outside. Also, the connection between the families is lack of landscaping making the outdoor environment unattractiveat all.

Our investigation revealed that, with accommodating visitors coming from surrounding cities for short-term stay, usually 1-2 days, tourism businesses in Renjiatai area is mainly focused on the home stay service. As a result, landscaping design has always been ignored.

\section{DESIGN STREATGY}

With Renjiatai trial our goal, based on the green deign, is to improve both indoor and outdoor environment of the family hotels in this area with reasonable expense. The bright spot of this project, green design goes through the entire project. It applies not only on the architecture but also on the future management.

\section{A. Green Archetecture}

In order to fit our buildings into the nature perfectly, we explored the idea of green architecture from designing to carrying out the rebuilt. We realized that one of the biggest issues is the concrete ground all over the village. Concrete makes the cooling system working in an inefficient way, especially in summer, which is by chance the busiest season in this area. As a result, waste plenty of energy and on the other hand, in return, the moisture in the house would do harm to the wall in the long run.

In accomplish of the green architecture policy, this moisture issue goes to the top to be solved. Our proposal reserved the original double pitch roof, which is designed to facilitate recycle the rain. In addition, all the rebuilt temporary buildings in the yards have been removed. Doing this to free up the yard with as much garden as possible. Bushes in the back yards recommended introducing vine, apple or fig, etc. We introduced breathing bricks for the ground tiles wherever needs, but grassand plants are the priorities. We also replaced the concrete on the outside wall with bricks for its tremendous advantages on the breathing function and low costs (1).

\section{B. Water Resources}

As another component of this project, the modification of the usage of water resourcesis of great importance. The proposal coves economizing on the water, rains recycle system, introducing non-tap water, improvement of water sustain, reuseing the AC cooling water (2).

Low-volume flashing design has been introduce into our project to apply on the faucets, showerheads and toilets. The original double pitch roofs in this area enable the recycle of the rains. We introduced recycle containers to collect the rains for watering garden and supporting the water plants and animals. On the other hand, the rains are better for the plants itselves(3). Therefore, our fundamental starting point here is, to the best extend, taking advantage of every single resource.

\section{Process of Waste Maerials}

Process of the wastes has been taken as another important component of this project. As the natural but inevitable outcome of the service business, especially in a high density, the proposal for the processing procedure come up to our project very seriously. We introduced classifying the wastes as recyclable and organic into processing system. We recommended useing reusable and recyclable gears as much as possible. And the organic wastes could be used as fertilizer with proper process. At same time, green and organic planting is a good idea for visitors' involved activities as well.

\section{Extend the Ecotourism}

Whenever a tourism and resorts zone has been developed on a sustainable way, the concept of green and ecotourism comes up to be the extraordinary aspect. In our project, we devoted to exploring the strategies of pursuing the best economic profits as well as customers' accomplishments, but the most important, we persisted the green ecotourism. Environment could never be compromised with economic development (4).

In detail, we proposed the following strategies,

a) Apply the local products to the home stay bussiness

b) Employ reisdents

c) Keep the orignal neighborhood tridations

d) Help-out throughout the neighborhood, avoid repeated investiment

e) Be dominate in improving village environment

In addition to the owners of the family hotels, the visitors could also play a key role in protecting the shared environment. Proper education of how and what can be done to help the neighborhood undergo a sustainable and healthy development will be passed over from the owners to the customers.

\section{E. Green design leads the visitors}

The green design has been conducted to its receivers, the visitors through out our project. For instance, we proposed to emphasize the waste classification facility, which will facilitate the recycle of waste materials in return. Customers would be encouraged to use personal cleaning gears instead of disposable stuff. Intelligent bike rental will be introduced into the zone as well, providing the customer a facilitating, environmental friendly transportation around the community. Customers would be able to check out information and guide at the newly developed reception desk. We are hoping our core concept, green design would be integrated into the activities that our customers would get involved during their vocation. By doing this, healthy and environment protectable tourism system comes into reality gradually.

\section{CONCLUSION}

Renjiatai trial accomplishes the green design for the family hotels. Taken the financial situation into consideration, we tried to propose a detailed and low-expense design. Our design aims at sponsoring the citizens of recalls of rural life style with its traditional architectures and real tunes. Our 
design inspired by 'Tales of the new era: Language and conversation' (5). In conclusion, our motivation of daily life comes from original environment from our natural deep heart. With your real feelings, you will encounter wonderful scenery wherever you go.

\section{ACKNOWLEDGEMENT}

This project is supported by outstanding artistic science of Shandong,2016, \#1607265

\section{REFERENCES}

[1] Naveh, Z. , 1991.Some remarks on recent developments in landscape ecology as a transdisciplinary ecological and geographical science. Landscape Ecology 5(2):65-73.

[2] Michell,J.,1975.The Earth Spirit. Thames and Hudson Ltd., New York.

[3] Kongjian, Y. 1990b, Ideal environmetal pattern and ecological view of Chinese. Proceeding of Peiking Forestry University.12(1)10-17

[4] Kongjian Y. 1991c, Identification of contenment landscaping and Design of entire humanity ecological system,Chinese forestry press. pp.161-170.

[5] Yiqing L, Tales of new era, language and conversation, Shanghai ancient books 202-203. 